\title{
The effects and safety of omega-3 fatty for acute lung injury: a systematic review and meta-analysis
}

\author{
Zhongjie Huang $^{1 \dagger}$, Jianming Zheng ${ }^{2 \dagger}$, Wencheng Huang ${ }^{1}$, Meihao Yan ${ }^{1}$, Liyue Hong ${ }^{1}$, Yuancheng Hong ${ }^{1 *}$, \\ Runnv Jin ${ }^{1}$, Xincheng Huang ${ }^{1}$, Hongtao Fan ${ }^{1}$, Huiling Chen ${ }^{1}$, Heping Yang ${ }^{1}$, Weiping Su ${ }^{1}$ and Xiaoping Huang
}

\begin{abstract}
Background: Several randomized controlled trials (RCTs) have compared the treatment of acute lung injury (ALI) with omega-3 fatty, yet the results remained inconsistent. Therefore, we attempted this meta-analysis to analyze the role of omega-3 fatty in the treatment of ALI patients.

Methods: We searched PubMed databases from inception date to October 31, 2019, for RCTs that compared the treatment of ALI with or without omega-3 fatty. Two authors independently screened the studies and extracted data from the published articles. Summary mean differences (MD) with 95\% confidence intervals (CI) were calculated for each outcome by fixed- or random-effects model.
\end{abstract}

Results: Six RCTs with a total of 277 patients were identified, of whom 142 patients with omega-3 fatty acid treatment and 135 patients without omega-3 fatty treatment. Omega-3 fatty treatments significantly improve the $\mathrm{PaO}_{2}(\mathrm{MD}=13.82,95 \% \mathrm{Cl}$ 8.55-19.09), $\mathrm{PaO}_{2} / \mathrm{FiO}_{2}(\mathrm{MD}=33.47,95 \% \mathrm{Cl} 24.22-42.72)$, total protein (MD $\left.=2.02,95 \% \mathrm{Cl} 0.43-3.62\right)$ in ALI patients, and omega-3 fatty acid treatments reduced the duration of mechanical ventilation $(\mathrm{MD}=-1.72,95 \% \mathrm{Cl}-2.84$ to -0.60$)$ and intensive care unit stay $(\mathrm{MD}=-1.29,95 \% \mathrm{Cl}-2.14$ to -0.43$)$ in ALI patients.

Conclusions: Omega-3 fatty can effectively improve the respiratory function and promote the recovery of ALI patients. Future studies focused on the long-term efficacy and safety of omega-3 fatty use for ALI are needed.

Keywords: Omega-3 fatty, Acute lung injury, Treatment, Meta-analysis, Review

\section{Background}

Acute lung injury (ALI) is a very common kind of critically ill disease in the clinic, which is caused by various intrapulmonary and external factors such as severe trauma, shock, acidosis, or serious infection $[1,2]$. If left untreated, it may progress into acute respiratory distress syndrome (ARDS) with high mortality [3]. In the past decade, great progress has been made in the management of

\footnotetext{
* Correspondence: qiyan20070901@163.com

${ }^{\dagger}$ Zhongjie Huang and Jianming Zheng contributed equally to this work. 'Department of Respiratory Medicine, Quanzhou Strait Hospital, No.180 Huayuan Road, Fengze District, Quanzhou 362000, Fujian Province, China Full list of author information is available at the end of the article
}

patients with ALI and ARDS. However, the mortality of ALI/ARDS is still high with a range of 40 to $31 \%[4,5]$. In addition to infection control, low tidal volume protective lung mechanical ventilation and nutritional treatment of ARDS/ALI play an important role in the treatment strategies [6-8], especially the provision of calories by fat nutrition is a key part [9].

At present, the fat emulsions used in clinical practice are mostly based on soybean oil. Soybean oilbased fat emulsions are rich in long-chain fat emulsions, which can affect granulocyte activity under severe stress such as trauma and infection, resulting in impaired immune function and increased lipid 
peroxidation, which in turn increases organ function damage $[10,11]$. This tendency to increase the inflammatory response often makes the use of soybean oil-based fat emulsions in a dilemma clinically. In recent years, omega-3 fatty acids have attracted much attention due to their ability to reduce inflammation and regulate immunity. It has been reported [12, 13] that it can inhibit inflammation and regulate immunity in many diseases. It has good effects in the treatment of severe patients such as sepsis and systemic inflammatory response syndrome [14, 15]. Compared to traditional fat emulsions, omega- 3 fatty shows its superiority in nutritional therapy for critically ill patients [16]. However, the studies on the effects of omega-3 fatty for the treatment of ALI are still lacking.

Based on literature review, we have found that there are several randomized controlled trials (RCTs) focusing on the omega-3 fatty in the treatment of ALI, yet the results have remained inconsistent. Furthermore, there are very few related meta-analyses on the role of omega-3 fatty acids in the treatment of ALI; further investigations are needed. Therefore, we attempted to conduct this meta-analysis to evaluate the efficacy and safety of omega-3 fatty in the treatment of ALI, to provide insights into the clinical management of ALI.

\section{Methods}

We attempted to conduct and report this meta-analysis in compliance with the Preferred Reporting Items for Systematic Reviews and Meta-Analyses (PRISMA) [17].

\section{Literature search}

Relevant RCTs on the role of omega-3 fatty in the treatment of ALI were screened and identified. We searched PubMed, EMBASE, Cochrane library, China National Knowledge Infrastructure (CNKI), Wanfang Database, and China Biomedical Literature Database (CBM) for relevant trials published in English or Chinese up to October 31, 2019. The following search terms were used: "omega-3; fish oil; $\omega-3$; acute lung injury; ALI; acute respiratory distress syndrome; ARDS." We adopted those search terms with combined Boolean operators "AND" or "OR" in every database. Besides, relevant systematic reviews and meta-analyses from those databases were identified, and their bibliographies were scrutinized for

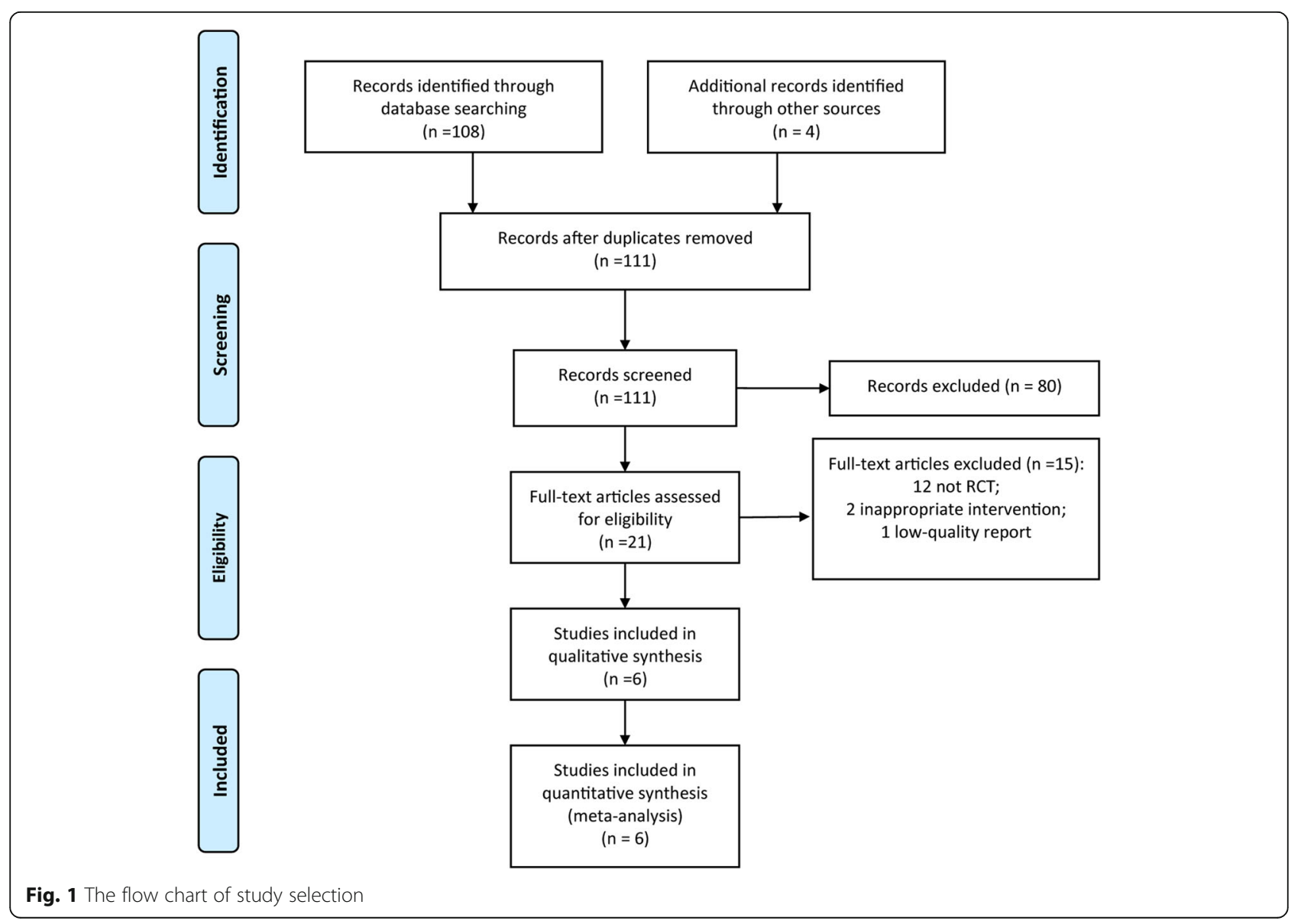


Table 1 The characteristics of the included RCTs

\begin{tabular}{|c|c|c|c|c|c|c|}
\hline Studies & Countries & Group & Participants & $\begin{array}{l}\text { Age } \\
\text { (years) }\end{array}$ & $\begin{array}{l}\text { Length } \\
\text { of diet }\end{array}$ & Conclusions \\
\hline \multirow[t]{2}{*}{$\begin{array}{l}\text { Dai } \\
2009\end{array}$} & China & $\begin{array}{l}\text { Omega-3 } \\
\text { fatty acids }\end{array}$ & 17 & $\begin{array}{l}39.5 \pm \\
5.8\end{array}$ & 1 week & $\begin{array}{l}\text { Omega- } 3 \text { fatty acids are beneficial to the recovery of respiratory function in } \\
\text { patients with ARDS }\end{array}$ \\
\hline & & Control & 17 & & & \\
\hline \multirow[t]{2}{*}{$\begin{array}{l}\text { Gupta } \\
2010\end{array}$} & India & $\begin{array}{l}\text { Omega-3 } \\
\text { fatty acids }\end{array}$ & 31 & $\begin{array}{l}51.16 \pm \\
15.58\end{array}$ & 1 week & $\begin{array}{l}\text { In ventilated patients with ARDS, intravenous omega-3 fatty acids alone do not im- } \\
\text { prove ventilation, length of ICU stay, or survival }\end{array}$ \\
\hline & & Control & 30 & $\begin{array}{l}46.63 \pm \\
16.44\end{array}$ & & \\
\hline \multirow[t]{2}{*}{$\begin{array}{l}\text { Shen } \\
2010\end{array}$} & China & $\begin{array}{l}\text { Omega-3 } \\
\text { fatty acids }\end{array}$ & 20 & $\begin{array}{l}66.1 \pm \\
15\end{array}$ & 1 week & $\begin{array}{l}\text { Omega- } 3 \text { polyunsaturated fatty acid improves respiratory function and prognosis } \\
\text { in patients with ALI. }\end{array}$ \\
\hline & & Control & 19 & $\begin{array}{l}61.9 \pm \\
18.9\end{array}$ & & \\
\hline \multirow[t]{2}{*}{$\begin{array}{l}\text { Shen } \\
2011\end{array}$} & China & $\begin{array}{l}\text { Omega-3 } \\
\text { fatty acids }\end{array}$ & 22 & $\begin{array}{l}64.0 \pm \\
9.0\end{array}$ & 1 week & $\begin{array}{l}\text { The use of omega-3 polyunsaturated fatty acids helps to improve inflammatory } \\
\text { factor levels in ALI patients. }\end{array}$ \\
\hline & & Control & 21 & $\begin{array}{l}68.0 \pm \\
10.0\end{array}$ & & \\
\hline \multirow[t]{2}{*}{$\begin{array}{l}\text { Wang } \\
2011\end{array}$} & China & $\begin{array}{l}\text { Omega-3 } \\
\text { fatty acids }\end{array}$ & 26 & $\begin{array}{l}75.2 \pm \\
8.9\end{array}$ & 1 week & $\begin{array}{l}\text { Omega-3 fatty acids are beneficial to the recovery of respiratory function in ALI } \\
\text { patients, and it shortens the time of mechanical ventilation and length of ICU stay. }\end{array}$ \\
\hline & & Control & 22 & & & \\
\hline \multirow[t]{2}{*}{$\begin{array}{l}\text { Zhao } \\
2010\end{array}$} & China & $\begin{array}{l}\text { Omega-3 } \\
\text { fatty acids }\end{array}$ & 26 & $\begin{array}{l}40.2 \pm \\
6.1\end{array}$ & 1 week & $\begin{array}{l}\text { The omega- } 3 \text { polyunsaturated fatty acids enriched enteral nutrition solution can fa- } \\
\text { cilitate the recovery of respiratory function. }\end{array}$ \\
\hline & & Control & 26 & & & \\
\hline
\end{tabular}

ARDS acute respiratory distress syndrome, $A L l$ acute lung injury

further relevant trials, as were those of the RCTs included in the review.

\section{Eligibility criteria}

Two investigators independently reviewed the identified articles. The inclusion criteria for RCTs were as follows: (1) RCT design, (2) comparative analysis of ALI treatment with or without omega-3 fatty, and (3) the details of omega-3 fatty treatment and related outcomes were reported. The exclusion criteria were as follows: (1) case reports, reviews, editorial comments, meeting abstracts, and articles without applicable data; (2) studies with insufficient data, such as missing the standard deviation (SD); and (3) considerable overlaps between the authors and research centers among the published literature.

\section{Study selection}

The search results were imported into the software of Endnote X7 for literature management. Two authors independently reviewed the title, abstract, or descriptors of the identified studies and excluded the studies that clearly did not meet the inclusion criteria. After

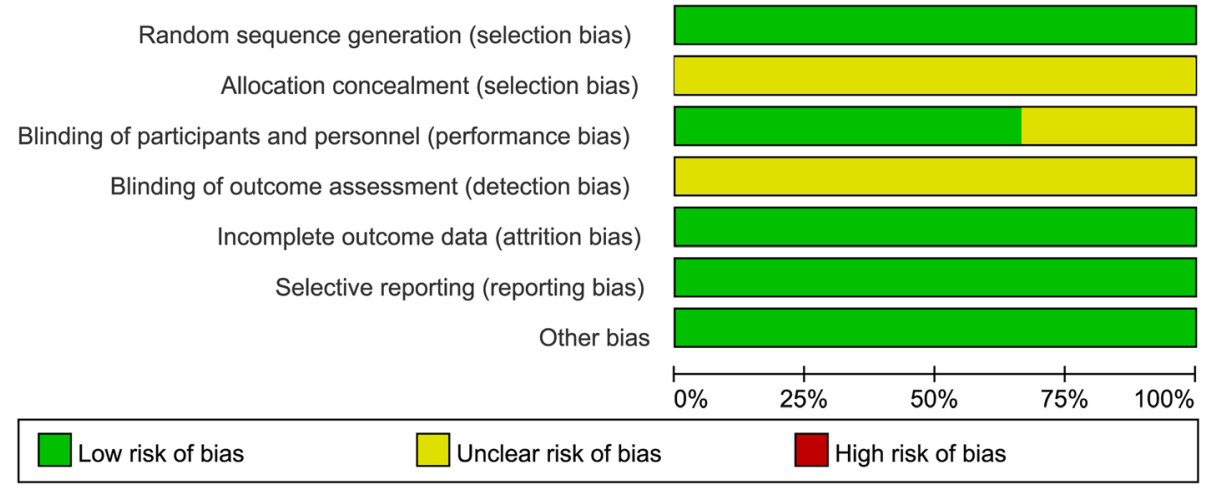

Fig. 2 Risk of bias graph 
excluding duplicate and apparently irrelevant studies, the full text of the remaining studies was reviewed to assess eligibility for inclusion. Any disagreements were resolved by discussion or by asking an independent third opinion.

\section{Data collection}

Two authors independently extracted the data from each study with a standardized data extraction checklist, which included the study characteristics (e.g., first author's name, publication year, journal, country where the study was conducted), characteristics of included study subjects (e.g., number of participants, age, gender distribution), details of omega-3 fatty treatment intervention, outcome variables (e.g., follow-up period), and study conclusion. Outcomes were extracted preferentially by intention to treat (ITT) at the end of follow-up. Quantitative data were extracted to calculate effect sizes. Data on effect size that could not be obtained directly were recalculated whenever possible or contacted the original authors for data. Any discrepancy was resolved by further consensus.

\section{Risk of bias assessment}

Two authors independently assessed the methodological quality of the included studies for major potential sources of bias using the Cochrane Collaboration's risk of bias tool, which includes the method of random sequence generation, allocation concealment, blinding of participants and personnel, blinding of outcome assessment, incomplete outcome data, selective reporting, and other sources of bias. We evaluated the methodological quality of every included RCT by rating each criterion as low, high, or unclear risk of bias. Any disagreements were resolved through further discussion whenever necessary.

\section{Statistical analysis}

The Review Manager Version 5.3 software was used for data analysis. All the data syntheses and interpretations were also performed by two authors independently to ensure the accuracy of the results. Binary outcomes were presented as Mantel-Haenszel-style odds ratios (OR) with 95\% confidence intervals (CIs). Continuous

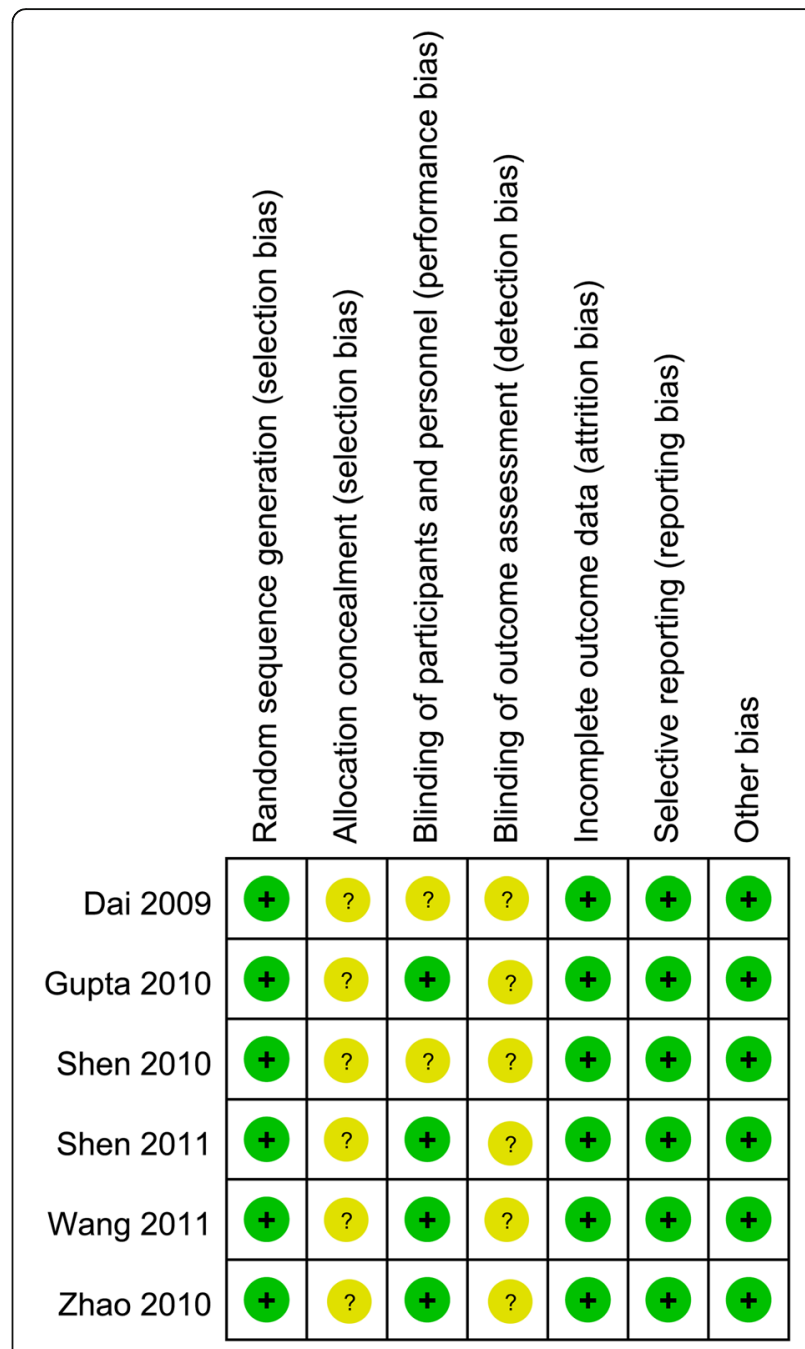

Fig. 3 Risk of bias summary

\begin{tabular}{|c|c|c|c|c|c|c|c|c|c|c|c|}
\hline \multirow[b]{2}{*}{ Study or Subgroup } & \multicolumn{3}{|c|}{ Omega-3 fatty acids } & \multicolumn{2}{|c|}{ Control } & \multirow{2}{*}{\multicolumn{2}{|c|}{ Total Weight }} & \multirow{2}{*}{$\begin{array}{l}\text { Mean Difference } \\
\text { |V. Fixed. } 95 \% \mathrm{Cl}\end{array}$} & \multirow{2}{*}{\multicolumn{3}{|c|}{$\begin{array}{l}\text { Mean Difference } \\
\text { IV.Fixed. } 95 \% \mathrm{CI}\end{array}$}} \\
\hline & Mean & SD & Total & Mean & SD & & & & & & \\
\hline Shen 2010 & 47.6 & 17.5 & 20 & 31.3 & 10.69 & 19 & $33.9 \%$ & $16.30[7.25,25.35]$ & & $=$ & \\
\hline Shen 2011 & 47.6 & 17.05 & 22 & 35 & 13.69 & 21 & $32.7 \%$ & $12.60[3.38,21.82]$ & & & \\
\hline Zhao 2010 & 84.9 & 14.04 & 26 & 72.4 & 19.14 & 26 & $33.4 \%$ & $12.50[3.38,21.62]$ & & $=$ & \\
\hline Total $(95 \% \mathrm{Cl})$ & & & 68 & & & 66 & $100.0 \%$ & $13.82[8.55,19.09]$ & & & \\
\hline $\begin{array}{l}\text { Heterogeneity: } \mathrm{Chi}^{2}= \\
\text { Test for overall effect: }\end{array}$ & $\begin{array}{l}44, \mathrm{df}=2 \\
=5.14(\mathrm{P}\end{array}$ & $\begin{array}{l}(P=0.8 \\
<0.000\end{array}$ & 1); $1^{2}=0 \%$ & & & & & & $\begin{array}{ccc}-20 & -10 & 0 \\
\text { Favours [Omega-3 fatty acids] }\end{array}$ & Favours [Control] & 20 \\
\hline
\end{tabular}

outcomes were reported as mean differences (MDs). A fixed-effect model was adopted in cases of homogeneity ( $P$ value of $\chi^{2}$ test $>0.10$ and $I^{2}<50 \%$ ), whereas a random-effect model was used in cases of obvious heterogeneity ( $P$ value of $\chi^{2}$ test $>0.10$ and $I^{2} \geq 50 \%$ ). Publication bias was evaluated by using funnel plots, and asymmetry was assessed by conducting Egger regression 


\begin{tabular}{|c|c|c|c|c|c|c|c|c|c|c|c|}
\hline \multirow[b]{2}{*}{ Study or Subgroup } & \multicolumn{3}{|c|}{ Omega-3 fatty acids } & \multicolumn{2}{|c|}{ Control } & & & \multirow{2}{*}{$\begin{array}{l}\text { Mean Difference } \\
\quad \text { IV, Fixed, } 95 \% \mathrm{Cl}\end{array}$} & \multirow{2}{*}{\multicolumn{3}{|c|}{$\begin{array}{l}\text { Mean Difference } \\
\text { IV. Fixed, } 95 \% \mathrm{Cl}\end{array}$}} \\
\hline & Mean & SD & Total & Mean & SD & Total & Weight & & & & \\
\hline Dai 2009 & 130.9 & 30.76 & 17 & 107.2 & 30.66 & 17 & $20.1 \%$ & $23.70[3.05,44.35]$ & & $\pi$ & \\
\hline Shen 2010 & 51.7 & 45.11 & 20 & 13.3 & 48.82 & 19 & $9.8 \%$ & $38.40[8.86,67.94]$ & & & \\
\hline Shen 2011 & 50 & 44.6 & 22 & 16 & 39.95 & 21 & $13.4 \%$ & $34.00[8.72,59.28]$ & & & \\
\hline Wang 2011 & 129.8 & 28.08 & 26 & 84.8 & 30.17 & 22 & $31.1 \%$ & $45.00[28.40,61.60]$ & & & \\
\hline Zhao 2010 & 169.8 & 28.08 & 26 & 144.8 & 38.28 & 26 & $25.7 \%$ & $25.00[6.75,43.25]$ & & & \\
\hline Total $(95 \% \mathrm{Cl})$ & & & 111 & & & 105 & $100.0 \%$ & $33.47[24.22,42.72]$ & & & \\
\hline $\begin{array}{l}\text { Heterogeneity: } \text { Chi }^{2}= \\
\text { Test for overall effect: }\end{array}$ & $\begin{array}{l}65, \mathrm{df}= \\
=7.09(\mathrm{P}\end{array}$ & $\begin{array}{l}(P=0.4 \\
<0.000\end{array}$ & & & & & & & $\begin{array}{ccc} & 1 \\
-50 & -25 & 1 \\
\text { Favours [Omega-3 fatty acids] }\end{array}$ & $\begin{array}{lc} & 1 \\
& 25 \\
\text { Favours [Control] }\end{array}$ & 50 \\
\hline
\end{tabular}

test. The statistical significance level was 0.05 in this present study.

\section{Results}

\section{Study selection}

Figure 1 shows a flow diagram of study selection. The electronic searches identified 111 literatures, and 80 reports were clearly not relevant after the first screening. The full text of 21 studies was retrieved for further indepth consideration, and 15 studies were excluded for several reasons: 12 studies were not RCT, 2 studies were with inappropriate intervention, and 1 study was a lowquality report. Finally, 6 RCTs [18-23] were included in this meta-analysis. References cited in published original and review papers were examined, and no further studies were found.

\section{Characteristics of included RCTs}

The characteristics of RCTs included in this present meta-analysis are presented in Table 1 . Of these included studies, one was performed in India [23], and the rest of the five studies in China [18-22]. The combined sample size across the 6 included studies was 277 participants, with 142 ALI patients with omega- 3 fatty treatment and 135 patients without omega-3 fatty acid treatment. The patient samples in the included studies were different with a range of 34 to 61 . For study results, one study did not support the use of omega-3 fatty in ALI patients, whereas the other studies all favored the use of omega-3 fatty in the treatment of ALI.

\section{Methodological quality of the included studies}

Figures 2 and 3 show the quality assessment of the studies in this present meta-analysis. All 6 included studies were randomized, but only two RCTs [21, 23] specified the method of randomization. All the RCTs did not report whether any allocation concealment process was used. Four RCTs [20-23] reported the design on blinding patients, personnel, and outcome assessors. No other significant biases among the included RCTs were found. Intention to treat (ITT) was performed for all patients.

\section{Outcomes}

The changes of $\mathrm{PaO}_{2}$ Three RCTs [19, 20, 22] reported the changes of $\mathrm{PaO}_{2}$ for ALI patients with or without omega-3 fatty acid treatment; the pooled data from the three RCTs revealed that the omega- 3 fatty acid treatments significantly improve the $\mathrm{PaO}_{2}$ in ALI patients (MD $=13.82,95 \%$ CI 8.55-19.09, $P<0.001, I^{2}=0 \%$; Fig. 4).

The changes of $\mathrm{PaO}_{2} / \mathrm{FiO}_{2}$ Five RCTs [18-22] reported the changes of $\mathrm{PaO}_{2} / \mathrm{FiO}_{2}$ for ALI patients with or without omega- 3 fatty treatment; the pooled data from the five RCTs revealed that the omega- 3 fatty acid treatments significantly improve the $\mathrm{PaO}_{2} / \mathrm{FiO}_{2}$ in ALI patients $\left(\mathrm{MD}=33.47,95 \% \mathrm{CI} 24.22-42.72, P<0.001, I^{2}=\right.$ 0\%; Fig. 5).

The changes of total protein Three RCTs [18, 21, 22] reported the changes of TP for ALI patients with or

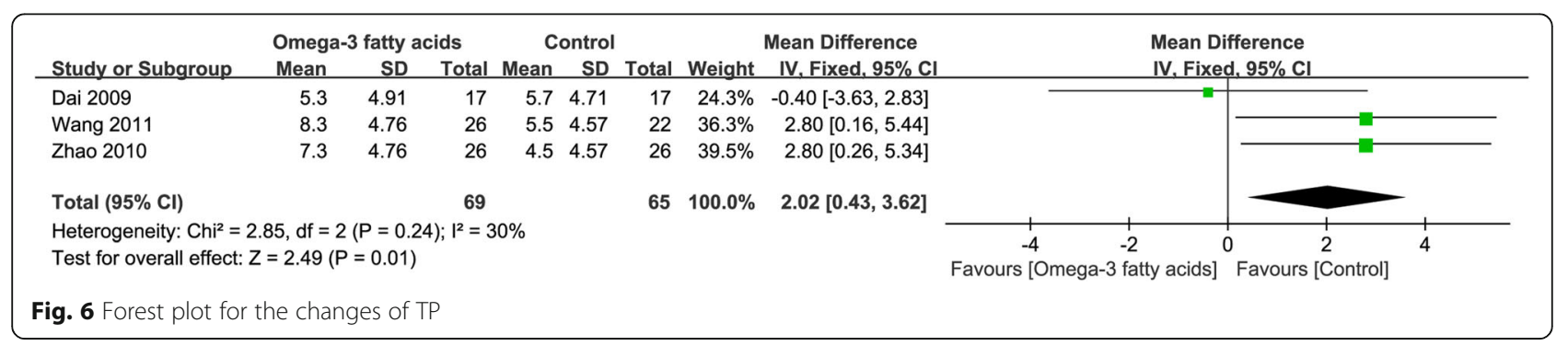


without omega-3 fatty treatment; the pooled data from the three RCTs revealed that the omega- 3 fatty acid treatments significantly increase the TP in ALI patients $\left(\mathrm{MD}=2.02,95 \%\right.$ CI $0.43-3.62, P=0.01, I^{2}$ $=30 \%$; Fig. 6).

The duration of mechanical ventilation Three RCTs [21-23] reported the duration of MV for ALI patients with or without omega-3 fatty treatment; the pooled data from the three RCTs revealed that the omega-3 fatty acid treatments significantly reduced the duration of MV in ALI patients (MD $=-1.72,95 \% \mathrm{CI}-2.84$ to $-0.60, P=0.003, I^{2}=0 \%$; Fig. 7).

The length of ICU stay Three RCTs [21-23] reported the length of ICU stay for ALI patients with or without omega-3 fatty acid treatment; the pooled data from the three RCTs revealed that the omega- 3 fatty acid treatments significantly reduced the length of ICU stay in ALI patients $(\mathrm{MD}=-1.29,95 \% \mathrm{CI}-2.14$ to $-0.43, P=$ 0.003, $I^{2}=59 \%$; Fig. 8 ).

\section{Subgroup and sensitivity analyses}

No subgroup analyses were performed in our study because the heterogeneity among the included RCTs in the synthesized results remained small. We attempted to evaluate publication bias by using a funnel plot if 10 or more RCTs were included [24]. However, the number of included RCTs was only six; we could not evaluate publication bias by using a funnel plot. Sensitivity analyses, which investigate the influence of one study on the overall risk estimate by removing one study in each turn, suggested that the overall risk estimates were not substantially changed by any single study.

\section{Discussion}

Patients with ALI are in a state of high metabolism, and it is necessary to provide nutritional support [25]. Besides, the nutritional support of critically ill patients should fully consider the tolerance of the damaged organ; critically ill patients should start EN as soon as the conditions permit [25]. It has been reported that early EN support improves immune function and protein levels in ARDS patients, which may reduce mortality and shorten the duration of MV and ICU stay [26]. With six RCTs included, the results of this present meta-analysis have indicated that omega- 3 fatty acids significantly improve the $\mathrm{PaO}_{2}, \mathrm{PaO}_{2} / \mathrm{FiO}_{2}$ increase the TP level, and reduce the length of MV and ICU stay for ALI patients. Therefore, the use of omega-3 fatty acids is a promising and effective treatment strategy for ALI.

The potential mechanism of omega-3 fatty acids for ALI treatment should be considered. A number of studies [27-29] have found that omega-3 fatty acids can regulate the synthesis of lipid mediators, release cytokines, and activate white blood cells and endothelial cells, thereby regulating the body's excessive inflammatory response to reduce the lung inflammation. Moreover, it is possible that omega- 3 fatty acids increase the patient's $\mathrm{PaO}_{2}$ and $\mathrm{PaO}_{2} / \mathrm{FiO}_{2}$ to improve the patient's respiratory function. Furthermore, omega- 3 fatty acids can reduce the concentration of IL-8, leukotriene, and neutrophils in the bronchial lavage fluid of patients, and reduce alveolar permeability, thereby improving patients' gas exchange [30, 31]. Meanwhile, it not only provides energy as a nutrient-supporting substance and maintains nitrogen balance, but also reduces insulin resistance and hyperlipidemia [32]. However, the potential risks of omega-3 fatty acid use should also be concerned. Two included RCTs [21, 22] reported the adverse events after the use of omega-3 fatty, mainly diarrhea, bloating, and gastric contents reflux. It can be related to that after long-term or unreasonable use of antibiotics, the intestinal flora is dysfunctional, which can easily lead to diarrhe $\mathrm{a}[33]$. And it is possible that the nutrient solution temperature is too low [34]. The occurrence of diarrhea is negatively associated with the serum protein levels [35]. Attention should be paid to the speed of infusion; the temperature of the nutrient solution should also be appropriate.

The pathological feature of ALI is pulmonary edema caused by increased pulmonary capillary permeability; the pathological basis of which is neutrophil-mediated local inflammatory response in the lung [36]. Pathophysiological changes were mainly due to increased Qs/ Qt and imbalance of ventilation/blood flow ratio [37]. The application of omega-3 fatty acids not only can quickly reduce the inflammatory reaction of lung tissue,

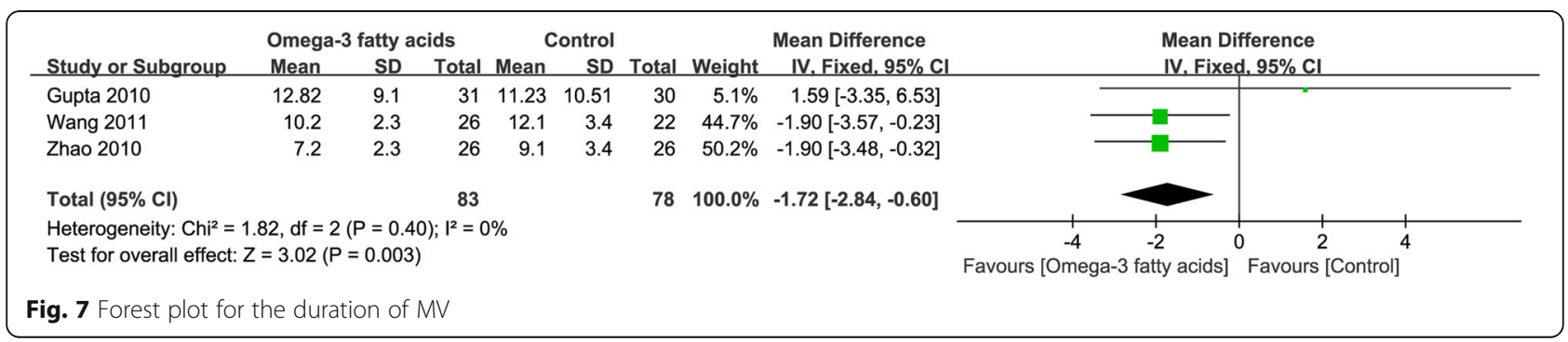




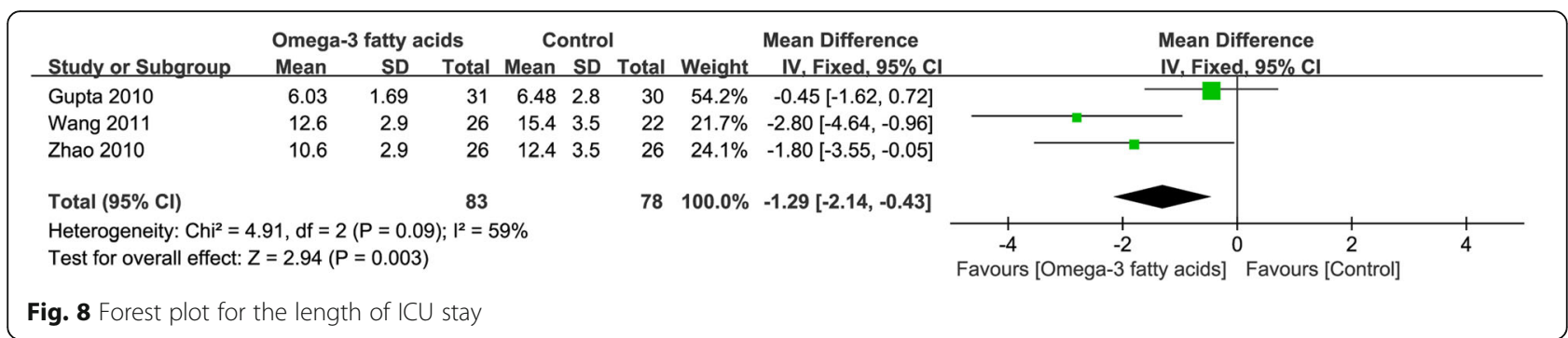

but also can transform LTB4, which aggravates inflammatory reaction, into LTB5 series, which is less active, thereby significantly reducing pulmonary edema, improving the pulmonary vascular permeability [38-40]. Besides, as specific immunonutrients, omega- 3 fatty can regulate the activity of lipid mediators, cytokines, and endothelial cell, thereby regulating the excessive inflammatory response of the body under infection and trauma [41]. Given all this together, the use of omega-3 fatty may be a useful adjuvant therapy for ALI patients.

The limitations existed in this study must be considered. Firstly, the number of RCTs included in this study is too small, and five out of six RCTs were from China, and the representativeness is poor. Secondly, the potential risk of bias in the allocation concealment process, blinding of researchers, and blinding of outcome assessments must be considered since the information on those issues remains unclear; omega-3 fatty treatment was associated with the reduced days of ICU for ALI patients, but the result should be taken cautiously. Further studies with strict design are needed. Thirdly, no relevant economic indicators were reported among included RCTs; thus, we could not perform analysis on this issue. Future clinical trials should focus on collecting and reporting relevant economic data to evaluate the cost of omega-3 fatty acid treatment. And the selected indicators should reflect the purpose of the study as much as possible with longer follow-up period.

In conclusion, as a kind of nutritional preparation, omega-3 acids can improve the respiratory function and respiratory status of ALI patients by increasing $\mathrm{PaO}_{2}$ and $\mathrm{PaO}_{2} / \mathrm{FiO}_{2}$. Meanwhile, it can increase the TP level, and reduce the length of MV and ICU stay of ALI patients. Therefore, omega-3 fatty may be a potential effective and safe strategy for the ALI treatment. Future larger-scale RCTs are needed to further evaluate the timing and dosage of omega-3 fatty application in ALI treatment.

\section{Abbreviations}

RCTs: Randomized controlled trials; ALI: Acute lung injury; OR: Odds ratios; MD: Mean differences; Cl: Confidence intervals; ARDS: Acute respiratory distress syndrome; CNKI: China National Knowledge Infrastructure; CBM: China Biomedical Literature Database; ITT: Intention to treat; TP: Total protein; MV: Mechanical ventilation; PUFA: Polyunsaturated fatty acids

\section{Acknowledgements}

None.

Authors' contributions

$Z H, J Z$ and $Y H$ designed the research; $Z H, J Z, W H, M Y, L H, R J, X H, H F$ and $\mathrm{HC}$ conducted the research; ZH, JZ, HY, WS and XH analyzed the data; $Z \mathrm{H}$ wrote the first draft of the manuscript; and $\mathrm{ZH}, J \mathrm{Z}$ and $\mathrm{YH}$ had primary responsibility for the final content. All authors read and approved the final manuscript.

\section{Funding}

None.

Availability of data and materials

All data generated or analyzed during this study are included in this published article.

Ethics approval and consent to participate

None.

Consent for publication

Not applicable.

\section{Competing interests}

The authors declare that they have no competing interests.

\section{Author details}

${ }^{1}$ Department of Respiratory Medicine, Quanzhou Strait Hospital, No.180 Huayuan Road, Fengze District, Quanzhou 362000, Fujian Province, China.

${ }^{2}$ Department of Infection, Quanzhou Strait Hospital, No.180 Huayuan Road, Fengze District, Quanzhou 362000, Fujian Province, China.

Received: 12 March 2020 Accepted: 14 June 2020

Published online: 03 September 2020

\section{References}

1. Matthay MA, Zemans RL, Zimmerman GA, Arabi YM, Beitler JR, Mercat A, et al. Acute respiratory distress syndrome. Nat Rev Dis Primers. 2019;5(1):18.

2. Roubinian NH, Triulzi DJ. Transfusion-associated circulatory overload and transfusion-related acute lung injury: etiology and prevention. Hematol Oncol Clin North Am. 2019;33(5):767-79.

3. Gossman W, Peniston Feliciano HL, Mahapatra S: Acute respiratory distress syndrome (ARDS). In: StatPearls. edn. Treasure Island (FL); 2019.

4. Erickson SE, Martin GS, Davis JL, Matthay MA, Eisner MD, Network NNA. Recent trends in acute lung injury mortality: 1996-2005. Crit Care Med. 2009; 37(5):1574-9.

5. Spragg RG, Bernard GR, Checkley W, Curtis JR, Gajic O, Guyatt G, et al. Beyond mortality: future clinical research in acute lung injury. Am J Respir Crit Care Med. 2010;181(10):1121-7.

6. Mokra D, Mikolka P, Kosutova P, Mokry J: Corticosteroids in acute lung injury: the dilemma continues. Int J Mol Sci 2019, 20(19).

7. Dushianthan A, Cusack R, Burgess VA, Grocott MP, Calder PC. Immunonutrition for acute respiratory distress syndrome (ARDS) in adults. Cochrane Database Syst Rev. 2019;1:CD012041.

8. Chen JJ, Deng JS, Huang CC, Li PY, Liang YC, Chou CY, et al. P-Coumaricacid-containing adenostemma lavenia ameliorates acute lung injury by activating AMPK/Nrf2/HO-1 signaling and improving the anti-oxidant response. Am J Chin Med. 2019:1-24. 
9. Stapleton RD, Martin TR, Weiss NS, Crowley JJ, Gundel SJ, Nathens AB, et al. A phase II randomized placebo-controlled trial of omega-3 fatty acids for the treatment of acute lung injury. Crit Care Med. 2011;39(7):1655-62.

10. King HM, Cosslett AG, Thomas CP, Price-Davies R. A HPLC method to monitor the occurrence of lipid peroxidation in intravenous lipid emulsions used in parenteral nutrition using in-line UV and charged aerosol detection. Clin Nutr ESPEN. 2018;28:96-102.

11. Fell GL, Anez-Bustillos L, Dao DT, Baker MA, Nandivada P, Cho BS, et al. Alpha-tocopherol in intravenous lipid emulsions imparts hepatic protection in a murine model of hepatosteatosis induced by the enteral administration of a parenteral nutrition solution. PLoS One. 2019;14(7):e0217155.

12. Baker MA, Cho BS, Anez-Bustillos L, Dao DT, Pan A, O'Loughlin AA, et al. Fish oil-based injectable lipid emulsions containing medium-chain triglycerides or added alpha-tocopherol offer anti-inflammatory benefits in a murine model of parenteral nutrition-induced liver injury. Am J Clin Nutr. 2019; 109(4):1038-50.

13. Kristine Koekkoek W, Panteleon V, van Zanten AR. Current evidence on omega-3 fatty acids in enteral nutrition in the critically ill: a systematic review and meta-analysis. Nutrition. 2019;59:56-68.

14. Parikh R, Bates JHT, Poynter ME, Suratt BT, Parsons PE, Kien CL, et al. Pharmacokinetics of omega-3 fatty acids in patients with severe sepsis compared with healthy volunteers: a prospective cohort study. Clin Nutr. 2019.

15. Singer P, Blaser AR, Berger MM, Alhazzani W, Calder PC, Casaer MP, et al. ESPEN guideline on clinical nutrition in the intensive care unit. Clin Nutr. 2019;38(1):48-79.

16. Klek S. Omega-3 fatty acids in modern parenteral nutrition: a review of the current evidence. J Clin Med. 2016;5(3):34

17. Shamseer L, Moher D, Clarke M, Ghersi D, Liberati A, Petticrew M, et al. Preferred reporting items for systematic review and meta-analysis protocols (PRISMA-P) 2015: elaboration and explanation. BMJ. 2015;350:g7647.

18. Dai F, Zhao Z. Application of enteral nutrient solution rich in omega-3 fatty acids in patients with ARDS. Mod Pract Med. 2009;21(6):588-9.

19. Shen $Y$, Shi $X$. Therapeutic effect of $\omega-3$ polyunsaturated fatty acid on acute lung injury. Chin J Microecol. 2010;22(7):640-2.

20. Shen $Y$, Shi $X$, Wu A. Effects of omega-3 polyunsaturated fatty acids on plasma TNF-a, IL-6 and IL-10 in patients with acute lung injury. Strait Pharm J. 2011:23(6):251-4.

21. Wang R, Gao D, Gong W, Xu L, Liu C. Lung protection of omega-3 fatty acids in elderly patients with acute lung injury induced by mechanical ventilation. Med J Clin Res. 2011;28(8):1478-9.

22. Zhao Z, Dai F, He G, Luo W. Lung protection of omega-3 fatty acids in patients with acute respiratory distress syndrome undergoing mechanical ventilation. Parent Enteral Nutr. 2010;17(5):266-9.

23. Gupta A, Govil D, Bhatnagar S, Gupta S, Goyal J, Patel S, et al. Efficacy and safety of parenteral omega 3 fatty acids in ventilated patients with acute lung injury. Indian J Crit Care Med. 2011;15(2):108-13.

24. Duval S, Tweedie R. Trim and fill: a simple funnel-plot-based method of testing and adjusting for publication bias in meta-analysis. Biometrics. 2000; 56(2):455-63.

25. Turner KL, Moore FA, Martindale R. Nutrition support for the acute lung injury/adult respiratory distress syndrome patient: a review. Nutr Clin Pract. 2011:26(1):14-25.

26. Raghavendran K, Napolitano LM. ALI and ARDS: challenges and advances. Crit Care Clin. 2011:27(3):xiii-xiv.

27. Scorletti E, Byrne CD. Omega-3 fatty acids and non-alcoholic fatty liver disease: evidence of efficacy and mechanism of action. Mol Asp Med. 2018; 64:135-46.

28. Abdelhamid AS, Brown TJ, Brainard JS, Biswas P, Thorpe GC, Moore HJ, et al. Omega-3 fatty acids for the primary and secondary prevention of cardiovascular disease. Cochrane Database Syst Rev. 2018;11:CD003177.

29. Lee HJ, Han YM, An JM, Kang EA, Park YJ, Cha JY, et al. Role of omega-3 polyunsaturated fatty acids in preventing gastrointestinal cancers: current status and future perspectives. Expert Rev Anticancer Ther. 2018;18(12): 1189-203.

30. He GZ, Dong LG, Cui XY, Chen XF. Zhang R: limpact of glutamine and omega-3 polyunsaturated fatty acids on intestinal permeability and lung cell apoptosis during intestinal ischemia-reperfusion injury in a rat model]. Zhonghua Wei Chang Wai Ke Za Zhi. 2012;15(5):484-9.

31. He GZ, Dong LG, Chen XF, Zhou KG, Shu H. Lymph duct ligation during ischemia/reperfusion prevents pulmonary dysfunction in a rat model with omega-3 polyunsaturated fatty acid and glutamine. Nutrition. 2011;27(5): 604-14.

32. Zayed EA, AinShoka AA, El Shazly KA. Abd El Latif HA: improvement of insulin resistance via increase of GLUT4 and PPARY in metabolic syndromeinduced rats treated with omega-3 fatty acid or I-carnitine. J Biochem Mol Toxicol. 2018;32(11):e22218.

33. Guo Q, Goldenberg JZ, Humphrey C, El Dib R, Johnston BC. Probiotics for the prevention of pediatric antibiotic-associated diarrhea. Cochrane Database Syst Rev. 2019;4:CD004827.

34. Pitta MR, Campos FM, Monteiro AG, Cunha AGF, Porto JD, Gomes RR. Tutorial on diarrhea and enteral nutrition: a comprehensive step-by-step approach. JPEN J Parenter Enteral Nutr. 2019;43(8):1008-19.

35. Hod K, Sperber AD, Maharshak N, Ron Y, Shapira I, David Z, et al. Serum cholinesterase activity is elevated in female diarrhea-predominant irritable bowel syndrome patients compared to matched controls. Neurogastroenterol Motil. 2018;30(12):e13464.

36. Qu L, Chen C, Chen Y, Li Y, Tang F, Huang H, et al. High-mobility group box 1 (HMGB1) and autophagy in acute lung injury (ALI): a review. Med Sci Monit. 2019;25:1828-37.

37. Gouda MM, Bhandary YP. Acute lung injury: IL-17A-mediated inflammatory pathway and its regulation by curcumin. Inflammation. 2019;42(4):1160-9.

38. Gammone MA, Riccioni G, Parrinello G, D' Orazio N. Omega-3 polyunsaturated fatty acids: benefits and endpoints in sport. Nutrients. 2018; 11(1):46.

39. Rutting S, Xenaki D, Lau E, Horvat J, Wood LG, Hansbro PM, et al. Dietary omega-6, but not omega-3, polyunsaturated or saturated fatty acids increase inflammation in primary lung mesenchymal cells. Am J Physiol Lung Cell Mol Physiol. 2018;314(6):L922-35.

40. Gutierrez-Delgado RI, Barraza-Villarreal A, Escamilla-Nunez C, HernandezCadena L, Garcia-Feregrino R, Shackleton C, et al. Effect of omega-3 fatty acids supplementation during pregnancy on lung function in preschoolers: a clinical trial. J Asthma. 2019;56(3):296-302.

41. Xu QL, Cai C, Qi WW, Xia ZG. Tang YZ: [influence of omega-3 polyunsaturated fatty acids on inflammation-related parameters in lung tissue of rats with severe scald]. Zhonghua Shao Shang Za Zhi. 2011;27(5): 358-62.

\section{Publisher's Note}

Springer Nature remains neutral with regard to jurisdictional claims in published maps and institutional affiliations.
Ready to submit your research? Choose BMC and benefit from:

- fast, convenient online submission

- thorough peer review by experienced researchers in your field

- rapid publication on acceptance

- support for research data, including large and complex data types

- gold Open Access which fosters wider collaboration and increased citations

- maximum visibility for your research: over $100 \mathrm{M}$ website views per year

At $\mathrm{BMC}$, research is always in progress.

Learn more biomedcentral.com/submissions 